\title{
Estudo de Parâmetros Bioquímicos de Éguas Gestantes, Puro Sangue Árabe
}

\author{
Maria Marina Unanian" ${ }^{* 1}$; Antonio Emidio D. Feliciano Silva ${ }^{1}$ e Airton Manzano ${ }^{2}$ \\ ${ }^{I}$ EMBRAPA-Cemtro Nacional de Recursos Genéticos e Biotecnologia (CENARGEN), SAIN - Parque Rural Av. W 5 \\ Norte, Brasília, DF. ${ }^{2}$ EMBRAPA-Centro de Pesquisa de Pecuária do Sudeste (CPPSE), Rod. Washington Luiz \\ km.234, São Carlos, SP.
}

\begin{abstract}
Metabolic rates were determined during the first and last gestation periods in Arab mares raised on Coastcross(Cynodon dactylon) pasture. For this study, blood, urine and stool samples were collected and body measures were taken. The mares had a weight gain, from the beginning till the end of the gestation, of 69,4 kg. Total protein values in the blood had shown a significant increase $(P<0,05)$ from the first to the last gestation month, while the albumin values decreased. The ratio of albumin : protein was constant during the gestation, reflecting balance in the protein feeding. The levels of calcium, phosphorus, magnesium, copper and zinc in the blood serum did not suffer any alteration during pregnancy. The same could be observed with total protein, glucose, creatinin and urea in the urine. The calcium and magnesium levels in the urine had an increase $(P<0,05)$ of the beginning to the end of gestation. Conversely, the phosphorus and potassium decreased $(P<0,05)$ due to increased mobilization of these elements in the final period, as result of fetal growth. In the stools, the protein, calcium, phosphorus and potassium levels decreased $(P<0,05)$ at the beginning and end of pregnancy, probably due to greater mobilization and an increase of nutritional needs. Analysis of the data allowed to conclude that most of the analyzed elements were eliminated in the urine, with the exception of the microminerals, which were eliminated in the stools. Considering the development of the animals during pregnancy the biochemical parameters obtained in this study can be considered as reference values for Arab pregnant mares raised exclusively on Coast-cross pasture.
\end{abstract}

Key words: Arab mares, biochemical parameters, gestation.

\section{INTRODUÇÃO}

Embora na espécie eqüina, a preocupação de oferecer dados de referência, tanto para diagnostico de doenças metabólicas como para manejo nutricional, originaram vários estudos, principalmente nos Estados Unidos e França (Hintz, 1992; Ralston, 1990 e 1992; Baucus et al. 1989; NRC, 1989; Wolter, 1975), no Brasil estes dados continuam sendo escassos.

Na criação de eqüinos uma das fases fisiológicas mais importantes é a gestação, que nesta espécie, em particular, que pode iniciar no "cio do potro" em no máximo 15 dias pós-parto. Para ocorrer a concepção e o desenvolvimento normal da gestação é imprescindível que o animal esteja em boas condições corporais, em conseqüência de uma alimentação equilibrada, garantindo com isto o sucesso da criação.

Com este propósito foram estudados vários parâmetros metabólicos em éguas na fase da formação e crescimento fetal, a fim de oferecer subsídios ao manejo nutricional e conhecimentos para se criarem éguas Puro Sangue gestantes exclusivamente a pasto. Isso deverá levar a redução do custo da criação, porem sem alterar a sua qualidade.

\section{MATERIAL E MÉTODOS}

O estudo foi realizado em 25 éguas gestantes, da raça Puro Sangue Árabe, pertencentes a criação da Embrapa, Centro de Pesquisa de Pecuária do Sudeste, em São Carlos, SP. As éguas foram

* Author for correspondence 
mantidas em pastagem de Coast-cross (Cynodon dactylon) durante toda a gestação numa lotação de 1,5 UA/ha, recebendo sal mineralizado (fosfato bicálcico 59,3\%, cloreto de sódio $39,6 \%$, sulfato ferroso $0,6 \%$, sulfato de manganês $0,2 \%$, óxido de zinco $0,2 \%$, sulfato de cobre $0,1 \%$, iodeto de potássio $0,002 \%$ )"ad libitum".

No inicio do experimento todos os animais foram submetidos a uma avaliação do estado corporal e saúde, sendo considerados normais. Durante todo período gestacional as éguas receberam os cuidados higiênicos e sanitários, como vermífugos e vacinas, próprios desta fase.

O acompanhamento dos animais foi feito durante os primeiros quatro meses de gestação e os últimos três. Os animais eram mensalmente conduzidos à área de manejo pela manha quando se coletava sangue através de vacutainer e urina através de sonda uretral, para análise de proteína total, albumina, creatinina, uréia, glicose por espectrofotometria, e macro (cálcio, magnésio, fósforo, potássio, sódio) e microminerais (zinco e cobre), por absorção atômica, segundo Unanian (1994). Os animais eram submetidos às mensurações do perímetro torácico e abdominal, e pesados. As condições corporais das éguas foram medidas por meio de escore segundo Henneke (1983). Esta avaliação foi baseada no acúmulo de gordura localizada na região escapular, costelas, vértebras cervicais, torácicas e lombares, e na inserção da cauda. Para avaliar a quantidade de gordura acumulada nestas regiões foi adotada uma escala de 1 a 8 : caquético (1), muito magro (2), magro (3), magro moderado (4), moderado musculoso (5), musculoso (6), gordo (7) e muito gordo (8). Ainda foram feitas coletas de fezes, pela manhã e a tarde, no terço inicial (45 e 90 dias) e no final ( 240 e 300 dias) da gestação, durante cinco dias consecutivos, a fim de determinar os mesmos minerais analisados no sangue e urina.

A média da gestação foi de $333 \pm 8$ dias, e todos os partos foram considerados normais.

$\mathrm{Na}$ pastagem foram realizadas amostragens no início e durante as chuvas, e no início e durante a seca, para se determinar a matéria seca (MS) e proteína bruta $(\mathrm{PB}), \quad \mathrm{e}$, ainda, os minerais medidos nas demais amostras, alem do teor de oxalato.

O consumo de sal mineralizado foi determinado pela diferença entre a quantidade oferecida e a sobra encontrada no cocho a cada 10 dias.

O consumo de sal mineralizado foi determinado pela diferença entre a quantidade oferecida e a sobra encontrada no cocho a cada 10 dias.

A análise dos resultados foi realizada pela ANOVA (Microcal Origin, 1996).

\section{RESULTADOS E DISCUSSÃO}

A análise da pastagem durante as quatro épocas do ano mostrou uma taxa baixa de proteína bruta (PB) no início das chuvas (Tabela 1).

Tabela 1. Médias de MS, PB e minerais do capim Coast-cross (Cynodon dactylon).

\begin{tabular}{|c|c|c|c|c|c|c|c|c|c|c|c|}
\hline \multirow{2}{*}{$\begin{array}{l}\text { Coleta } \\
\text { (mês) }\end{array}$} & $\mathrm{MS}$ & $\mathrm{PB}$ & $\mathrm{Ca}$ & $\mathrm{P}$ & $\mathrm{Mg}$ & $\mathrm{Na}$ & $\mathrm{K}$ & $\mathrm{S}$ & $\mathrm{Cu}$ & $\mathrm{Zn}$ \\
\hline & \multicolumn{9}{|c|}{$(\%)$} \\
\hline $\mathrm{C}_{1}$ & 93,6 & 3,9 & 0,25 & 0,09 & 0,14 & 0,02 & 0,64 & 0,13 & 3,1 & 23,0 \\
\hline $\mathrm{C}_{2}$ & 92,8 & 5,6 & 0,26 & 0,11 & 0,15 & 0,02 & 1,01 & 0,17 & 3,3 & 25,5 \\
\hline $\mathrm{C}_{3}$ & 94,9 & 5,8 & 0,27 & 0,11 & 0,21 & 0,01 & 1,06 & 0,25 & 6,4 & 38,8 \\
\hline $\mathrm{C}_{4}$ & 94,3 & 5,2 & 0,24 & 0,06 & 0,19 & 0,01 & 0,77 & 0,22 & 6,9 & 38,7 \\
\hline
\end{tabular}

$\mathrm{C}_{1}$ - novembro, início da chuvas, 45 dias de gestação

$\mathrm{C}_{2}$ - dezembro, chuvas, 90 dias de gestação

$\mathrm{C}_{3}$ - maio, início da seca, 240 dias de gestação

$\mathrm{C}_{4}$ - julho, seca, 300 dias de gestação 
$\mathrm{O}$ teor de oxalato, nas coletas $\mathrm{C}_{1}, \mathrm{C}_{2}, \mathrm{C}_{3}$ e $\mathrm{C}_{4}$, foi de $0,05,0,06,0,03$ e 0,03 , respectivamente. $\mathrm{O}$ consumo de sal variou de mês a mês. Agrupando os dados por épocas, resultou uma média de $101,56 \mathrm{~g}$ nas chuvas e 71,48 g na seca, por animal/dia.

Durante os meses de gestação, do primeiro ao último, as éguas aumentaram gradativamente seus pesos, escores e perímetros (Tabela 2), mostrando ter havido um desenvolvimento normal tanto das matrizes como do feto. Os resultados encontrados para peso e perímetros estiveram dentro do padrão da raça Puro Sangue Árabe (Silva et al., 1990; Unanian et al., 1994) e os escores indicaram boas condições corporais (Hines, 1985).

Tabela 2. Médias ( \pm erro padrão) de medidas corporais de éguas gestantes da raça Puro Sangue Árabe.

\begin{tabular}{|c|c|c|c|c|}
\hline \multirow{3}{*}{$\begin{array}{c}\text { Gestação } \\
\text { (mês) }\end{array}$} & \multicolumn{4}{|c|}{ Parâmetros } \\
\hline & \multirow[t]{2}{*}{ Peso (kg) } & \multirow[t]{2}{*}{ Escore (1 a 9) } & \multicolumn{2}{|c|}{ Perímetro $(\mathrm{cm})$} \\
\hline & & & Torácico & Abdominal \\
\hline $1^{\circ}$ & $411,3 \pm 8,5$ & $4,8 \pm 0,1$ & $171,3 \pm 1,6$ & $189,6 \pm 1,8$ \\
\hline $2^{\circ}$ & $415,5 \pm 7,2$ & $4,8 \pm 0,1$ & $174,3 \pm 1,7$ & $189,9 \pm 1,8$ \\
\hline $3^{\circ}$ & $417,6 \pm 6,8$ & $5,2 \pm 0,1$ & $174,8 \pm 1,6$ & $192,7 \pm 1,6$ \\
\hline $4^{\circ}$ & $425,3 \pm 6,2$ & $5,4 \pm 0,1$ & $176,4 \pm 1,6$ & $194,2 \pm 1,6$ \\
\hline $8^{\circ}$ & $462,7 \pm 6,2$ & $6,4 \pm 0,1$ & $182,8 \pm 1,0$ & $204,9 \pm 1,4$ \\
\hline $9^{\circ}$ & $471,0 \pm 6,6$ & $6,6 \pm 0,1$ & $183,9 \pm 1,3$ & $210,4 \pm 1,2$ \\
\hline $10^{\circ}$ & $481,1 \pm 8,3$ & $6,8 \pm 0,1$ & $180,0 \pm 1,0$ & $214,5 \pm 1,3$ \\
\hline Parto & $425,6 \pm 7,2$ & & & \\
\hline Ganho & $69,4 \pm 6,0$ & $2,1 \pm 0,2$ & $7,8 \pm 1,5$ & $26,1 \pm 1,4$ \\
\hline
\end{tabular}

Embora no mês de novembro, no início da gestação, a pastagem apresentasse baixo teor de PB (Tabela 1), não ocorreram alterações no peso e demais parâmetros maternos estudados, mostrando o grau de adaptação destes animais ao sistema de criação a pasto. Durante a gestação ocorreu uma média de ganho de peso de $69 \mathrm{~kg}$, constituído, na maioria, do peso dos neonatos (Tabela 3), acrescido dos envoltórios fetais e liquido. Considerando a média de ganho do escore de 2 pontos, observou-se que as éguas apresentaram desenvolvimento normal sem demasiado acúmulo de gordura, indesejável ao parto.

Tabela 3. Médias ( \pm erro padrão)de pesos de neonatos, ao nascimento, da raça Puro Sangue Árabe.

\begin{tabular}{|c|c|c|}
\hline \multicolumn{2}{|c|}{ Variáveis } & $\begin{array}{c}\text { Peso } \\
(\mathrm{kg})\end{array}$ \\
\hline \multirow{2}{*}{\multicolumn{2}{|c|}{$\begin{array}{r}\text { Sexo: Fêmeas } \\
\text { Machos } \\
\end{array}$}} & $39,5 \pm 2,3$ \\
\hline & & $42,8 \pm 2,3$ \\
\hline \multirow[t]{4}{*}{ Mês de cobertura: } & Julho & $39,5 \pm 3,1$ \\
\hline & Agosto & $38,8 \pm 3,1$ \\
\hline & Setembro & $35,9 \pm 3,2$ \\
\hline & Novembro & $48,6 \pm 3,2$ \\
\hline \multicolumn{2}{|c|}{ Média geral } & $40,7 \pm 1,8$ \\
\hline \multicolumn{2}{|c|}{ Relação com o peso materno } & $0,096 \pm 0,019$ \\
\hline
\end{tabular}

Os pesos dos neonatos situaram-se dentro do padrão da raça (Singh \& Raut, 1986; Unanian et $a l .$, 1994) não tendo sofrido influência do sexo, mês da cobertura e do nascimento, confirmando os resultados de Fuentes-Garcia et al. (1988). Os pesos (Tabela 3) se mantiveram numa relação de cerca de $10 \%$ do peso da égua. Não foi encontrada correlação entre estes pesos e os maternos, como também observado por Rogers et al. (1984). 
Os parâmetros bioquímicos e minerais obtidos no soro sangüíneo das éguas, apresentados nas Tabelas 4 e 5, foram semelhantes aos valores de referência descritos por Rossdale \& Ricketts (1980), Diet \& Wiesner (1984), Rogers et al. (1984) e Patterson et al. (1985).

Tabela 4. Médias ( \pm erro padrão) de parâmetros bioquímicos no soro sangüíneo de éguas gestantes da raça Puro Sangue Árabe.

\begin{tabular}{|c|c|c|c|c|c|}
\hline \multirow{3}{*}{$\begin{array}{c}\text { Gestação } \\
\text { (mês) }\end{array}$} & \multicolumn{5}{|c|}{ Parâmetros } \\
\hline & Proteína total & Albumina & Glicose & Creatinina & Uréia \\
\hline & \multicolumn{2}{|c|}{$(\mathrm{g} / 100 \mathrm{ml})$} & \multicolumn{3}{|c|}{$(\mathrm{mg} / 100 \mathrm{ml})$} \\
\hline $1^{\circ}$ & $6,79 \pm 0,07^{\mathrm{a}}$ & $3,09 \pm 0,07^{\mathrm{c}}$ & $79,92 \pm 2,06$ & $1,03 \pm 0,07$ & $37,59 \pm 2,26$ \\
\hline $2^{\circ}$ & $7,09 \pm 0,11^{\mathrm{ac}}$ & $2,72 \pm 0,07^{\mathrm{ab}}$ & $81,02 \pm 1,57$ & $1,17 \pm 0,06$ & $37,81 \pm 2,12$ \\
\hline $3^{\circ}$ & $7,23 \pm 0,10^{\text {bc }}$ & $2,75 \pm 0,06^{\mathrm{ab}}$ & $80,29 \pm 2,08$ & $1,07 \pm 0,06$ & $43,88 \pm 3,31$ \\
\hline $4^{\circ}$ & $7,28 \pm 0,08^{\mathrm{c}}$ & $2,71 \pm 0,04^{\mathrm{a}}$ & $78,53 \pm 2,55$ & $1,06 \pm 0,04$ & $38,68 \pm 2,37$ \\
\hline $8^{\circ}$ & $6,99 \pm 0,07^{\mathrm{ac}}$ & $2,79 \pm 0,04^{\mathrm{ab}}$ & $79,36 \pm 2,76$ & $1,02 \pm 0,05$ & $37,16 \pm 1,55$ \\
\hline $9^{\circ}$ & $6,91 \pm 0,30^{\mathrm{a}}$ & $2,77 \pm 0,04^{\mathrm{ab}}$ & $79,85 \pm 2,70$ & $1,14 \pm 0,06$ & $38,01 \pm 1,84$ \\
\hline $10^{\circ}$ & $7,05 \pm 0,10^{\mathrm{ac}}$ & $2,88 \pm 0,05^{\mathrm{b}}$ & $74,84 \pm 2,57$ & $1,19 \pm 0,05$ & $40,50 \pm 1,85$ \\
\hline
\end{tabular}

Os valores acompanhados de letras diferentes, dentro da mesma coluna, indicam significância ao nível de $\mathrm{P}<0,05$ pelo teste $\mathrm{T}$

Com exceção da concentração da proteína total e albumina (Tabela 4), os demais parâmetros não variaram em função dos meses de gestação estudados. O nível da albumina foi mais elevado no primeiro mês de gestação coincidindo com o mais baixo valor de proteína total. No entanto a proporção albumina : proteína total desde $01^{\circ}$ mês até o final da gestação se manteve constante conforme a proporção descrita por Rogers et al. (1985) para animais recebendo dietas protéicas equilibradas. Este fato foi ainda demonstrado pela concentração da uréia que constitui o indicador da alimentação protéica
(Felbinger, 1987). Os parâmetros sangüíneos encontrados no presente estudo foram semelhantes aos de Rossdale \& Rickets (1980) e Dietz \& Wiesner (1984), considerados como normais por estes autores. Não houve diferença $(\mathrm{P}>0,05)$ entre os teores de minerais determinados mensalmente (Tabela 5). Nos últimos três meses de gestação o crescimento do feto é linear, ocorrendo o aumento das necessidades de cálcio, magnésio e fósforo (Meyer \& Ahlswede, 1976). Assim mesmo, os níveis dos minerais maternos não sofreram alterações significantes $(\mathrm{P}>0,05)$.

Tabela 5. Médias ( \pm erro padrão) dos níveis de minerais no soro sangüíneo de éguas gestantes da raça Puro Sangue Árabe.

\begin{tabular}{|c|c|c|c|c|c|c|c|}
\hline \multirow{3}{*}{$\begin{array}{c}\text { Gestação } \\
\text { (mês) }\end{array}$} & \multicolumn{7}{|c|}{ Parâmetros } \\
\hline & $\mathrm{Ca}$ & $\mathrm{P}$ & $\mathrm{Mg}$ & K & $\mathrm{Na}$ & $\mathrm{Cu}$ & $\mathrm{Zn}$ \\
\hline & \multicolumn{3}{|c|}{$\mathrm{mg} \%$} & \multicolumn{2}{|c|}{$\mathrm{mEq} / \mathrm{l}$} & \multicolumn{2}{|c|}{ ppm } \\
\hline $1^{\circ}$ & $13,98 \pm 0,40$ & $3,93 \pm 0,23$ & $1,73 \pm 0,11$ & $4,59 \pm 0,18$ & $125,79 \pm 3,48$ & $1,31 \pm 0,06$ & $69,48 \pm 4,83$ \\
\hline $2^{\circ}$ & $14,59 \pm 0,34$ & $3,69 \pm 0,18$ & $1,79 \pm 0,08$ & $4,68 \pm 0,14$ & $123,30 \pm 2,64$ & $1,38 \pm 0,06$ & $76,31 \pm 3,80$ \\
\hline $3^{\circ}$ & $14,32 \pm 0,36$ & $3,95 \pm 0,13$ & $1,73 \pm 0,07$ & $4,34 \pm 0,14$ & $120,35 \pm 2,96$ & $1,47 \pm 0,06$ & $79,79 \pm 3,44$ \\
\hline $4^{\circ}$ & $14,11 \pm 0,30$ & $3,82 \pm 0,15$ & $1,74 \pm 0,08$ & $4,25 \pm 0,16$ & $116,01 \pm 2,24$ & $1,47 \pm 0,08$ & $79,93 \pm 5,24$ \\
\hline $8^{\circ}$ & $13,20 \pm 0,21$ & $3,51 \pm 0,13$ & $1,88 \pm 0,05$ & $4,26 \pm 0,14$ & $113,21 \pm 3,05$ & $1,56 \pm 0,09$ & $76,85 \pm 4,42$ \\
\hline $9^{\circ}$ & $12,89 \pm 0,24$ & $3,53 \pm 0,11$ & $1,81 \pm 0,07$ & $4,47 \pm 0,12$ & $119,97 \pm 2,61$ & $1,38 \pm 0,08$ & $74,74 \pm 7,59$ \\
\hline $10^{\circ}$ & $12,54 \pm 0,27$ & $3,38 \pm 0,14$ & $1,98 \pm 0,05$ & $4,85 \pm 0,12$ & $124,67 \pm 3,16$ & $1,22 \pm 0,05$ & $88,80 \pm 4,58$ \\
\hline
\end{tabular}

Os parâmetros bioquímicos da urina (Tabela 6) foram semelhantes aos descritos na literatura por Dietz \& Wiesner (1984). Segundo estes autores a glicosúria é pouco comum nos eqüinos, como também observado neste experimento. 
Tabela 6. Médias ( \pm erro padrão) dos parâmetros bioquímicos na urina de éguas gestantes da raça Puro Sangue Árabe.

\begin{tabular}{|c|c|c|c|c|}
\hline \multirow{2}{*}{$\begin{array}{c}\text { Gestação } \\
(\text { mês })\end{array}$} & \multicolumn{3}{|c|}{ Parâmetros } \\
\cline { 2 - 5 } & Proteína total & Glicose & Creatinina & Uréia \\
\cline { 2 - 5 } & \multicolumn{3}{|c|}{$\mathrm{mg} / 100 \mathrm{ml}$} & $\mathrm{g} / 1$ \\
\hline $1^{\circ}$ & $5,89 \pm 0,92$ & $9,64 \pm 1,98$ & $17,09 \pm 2,48$ \\
\hline $2^{\circ}$ & $5,98 \pm 0,50$ & $11,03 \pm 1,00$ & $149,06 \pm 14,37$ & $17,88 \pm 1,75$ \\
\hline $3^{\circ}$ & $6,76 \pm 0,51$ & $12,19 \pm 0,80$ & $116,61 \pm 16,70$ & $18,52 \pm 1,56$ \\
\hline $4^{\circ}$ & $6,37 \pm 0,51$ & $9,81 \pm 1,20$ & $121,19 \pm 15,52$ & $18,36 \pm 1,49$ \\
\hline $8^{\circ}$ & $6,43 \pm 0,54$ & $9,55 \pm 1,03$ & $125,86 \pm 16,33$ & $18,88 \pm 2,01$ \\
\hline $9^{\circ}$ & $5,52 \pm 0,60$ & $8,58 \pm 0,90$ & $112,90 \pm 13,63$ & $15,75 \pm 1,93$ \\
\hline $10^{\circ}$ & $6,33 \pm 0,63$ & $9,84 \pm 1,14$ & $123,91 \pm 12,51$ & $19,61 \pm 2,05$ \\
\hline
\end{tabular}

Não foi possível comparar os níveis dos minerais detectados na urina (Tabela 7) com os da literatura por falta de dados. Pelas concentrações obtidas, e considerando as condições de criação e estado físico dos animais deste trabalho (Tabelas 2 e 3 ), os dados poderiam ser considerados como normais, de referência, para a categoria animal estudada.

Tabela 7. Médias ( \pm erro padrão) dos níveis de minerais na urina de éguas gestantes da raça Puro Sangue Árabe.

\begin{tabular}{|c|c|c|c|c|c|}
\hline \multirow{2}{*}{$\begin{array}{c}\text { Gestação } \\
(\text { mês }\end{array}$} & \multicolumn{5}{|c|}{ Parâmetros } \\
\cline { 2 - 6 } & $\mathrm{Ca}$ & $\mathrm{P}$ & $\mathrm{Mg}$ & $\mathrm{K}$ & $\mathrm{Na}$ \\
\cline { 2 - 6 } & \multicolumn{3}{|c|}{$\mathrm{mg} \%$} & \multicolumn{2}{c|}{$\mathrm{mEg} / 1$} \\
\hline $1^{\circ}$ & & $0,79 \pm 0,29^{\mathrm{a}}$ & $43,80 \pm 10,44^{\mathrm{a}}$ & $264,80 \pm 49,16^{\mathrm{ab}}$ & $1,70 \pm 0,37^{\mathrm{ab}}$ \\
\hline $2^{\circ}$ & $68,56 \pm 12,44^{\mathrm{a}}$ & $0,91 \pm 0,12^{\mathrm{a}}$ & $79,27 \pm 09,79^{\mathrm{bc}}$ & $258,91 \pm 24,32^{\mathrm{ab}}$ & $2,28 \pm 0,30^{\mathrm{a}}$ \\
\hline $3^{\circ}$ & $50,11 \pm 12,31^{\mathrm{a}}$ & $0,86 \pm 0,13^{\mathrm{a}}$ & $61,04 \pm 07,76^{\mathrm{ab}}$ & $274,35 \pm 23,42^{\mathrm{a}}$ & $2,21 \pm 0,36^{\mathrm{a}}$ \\
\hline $4^{\circ}$ & $66,04 \pm 15,68^{\mathrm{a}}$ & $0,74 \pm 0,13^{\mathrm{a}}$ & $58,39 \pm 06,86^{\mathrm{ab}}$ & $252,62 \pm 23,28^{\mathrm{ab}}$ & $1,80 \pm 0,23^{\mathrm{ab}}$ \\
\hline $8^{\circ}$ & $159,48 \pm 25,66^{\mathrm{b}}$ & $0,32 \pm 0,09^{\mathrm{a}}$ & $76,59 \pm 08,63^{\mathrm{abc}}$ & $209,90 \pm 19,23^{\mathrm{b}}$ & $1,22 \pm 0,14^{\mathrm{b}}$ \\
\hline $9^{\circ}$ & $141,20 \pm 26,11^{\mathrm{b}}$ & $0,19 \pm 0,04^{\mathrm{b}}$ & $60,22 \pm 09,36^{\mathrm{ab}}$ & $178,90 \pm 19,72^{\mathrm{b}}$ & $1,23 \pm 0,11^{\mathrm{b}}$ \\
\hline $10^{\circ}$ & $210,66 \pm 28,75^{\mathrm{b}}$ & $0,23 \pm 0,04^{\mathrm{b}}$ & $92,44 \pm 0797^{\mathrm{c}}$ & $186,71 \pm 24,37^{\mathrm{b}}$ & $2,02 \pm 0,36^{\mathrm{a}}$ \\
\hline
\end{tabular}

Os valores acompanhados de letras diferentes, dentro da mesma coluna, indicam significância ao nível de $\mathrm{P}<0,05$ pelo teste $\mathrm{T}$.

Dentre os minerais estudados o cálcio apresentou valores mais baixos $(\mathrm{P}<0,05)$ nos meses iniciais da gestação, meses da formação fetal, mostrando ser o elemento mais mobilizado desta fase. A participação mais evidente do magnésio neste processo foi no primeiro mês de gestação, assim como do fósforo e potássio nos últimos meses. Os microelementos na urina apareceram apenas sob forma de traços, permitindo concluir que estes elementos não são excretados por esta via.

Com relação aos parâmetros encontrados nas fezes (Tabela 8) também não foi possível compará-los aos dados de literatura por falta de dados. 
Tabela 8. Médias de proteína bruta $(\mathrm{PB})$ e minerais nas fezes de éguas gestantes da raça Puro Sangue Árabe.

\begin{tabular}{|c|c|c|c|c|c|c|c|c|c|c|}
\hline \multirow{2}{*}{$\begin{array}{c}\text { Gestação } \\
\text { (dias) }\end{array}$} & \multicolumn{9}{|c|}{ Parâmetros } \\
\cline { 2 - 11 } & $\mathrm{PB}$ & $\mathrm{Ca}$ & $\mathrm{P}$ & $\mathrm{Mg}$ & $\mathrm{K}$ & $\mathrm{Na}$ & $\mathrm{S}$ & $\mathrm{Cu}$ & $\mathrm{Zn}$ \\
\cline { 2 - 10 } & \multicolumn{9}{|c|}{$(\%)$} & \multicolumn{3}{c|}{$(\mathrm{ppm})$} \\
\hline 45 & $7,87^{\mathrm{b}}$ & $0,37^{\mathrm{bc}}$ & $0,30^{\mathrm{a}}$ & 0,21 & $1,02^{\mathrm{b}}$ & $0,10^{\mathrm{a}}$ & 0,13 & $27,03^{\mathrm{b}}$ & $64,56^{\mathrm{a}}$ \\
\hline 90 & $9,25^{\mathrm{d}}$ & $0,37^{\mathrm{b}}$ & $0,47^{\mathrm{b}}$ & 0,20 & $0,19^{\mathrm{c}}$ & $0,15^{\mathrm{b}}$ & 0,14 & $40,58^{\mathrm{c}}$ & $70,73^{\mathrm{ab}}$ \\
\hline 240 & $8,48^{\mathrm{c}}$ & $0,48^{\mathrm{c}}$ & $0,59^{\mathrm{c}}$ & 0,22 & $0,81^{\mathrm{a}}$ & $0,40^{\mathrm{d}}$ & 0,15 & $23,20^{\mathrm{b}}$ & $118,23^{\mathrm{c}}$ \\
\hline 300 & $5,93^{\mathrm{a}}$ & $0,29^{\mathrm{a}}$ & $0,26^{\mathrm{a}}$ & 0,21 & $0,83^{\mathrm{a}}$ & $0,23^{\mathrm{c}}$ & 0,13 & $18,71^{\mathrm{a}}$ & $77,45^{\mathrm{b}}$ \\
\hline
\end{tabular}

Valores acompanhados de letras diferentes, dentro da mesma coluna, indicam significância ao nível de $\mathrm{P}<0,05$ pelo teste $\mathrm{T}$.

Pelos resultados obtidos através da análise de urina e das fezes observou-se que, a maior parte dos elementos estudados foram excretados, principalmente, por via urinária, com exceção dos microminerais.

Com base nos valores descritos na urina, e em função das condições físicas dos animais, sugere-se também considerar as concentrações encontradas nas fezes como de referência para a categoria animal estudada. A maioria dos elementos estudados nas fezes apresentaram valores menores no inicio e final da gestação, período de maior mobilização devido ao aumento das necessidades nutricionais, em função da formação e crescimento do feto (Hintz, 1992). Ficou evidente que a excreção dos microminerais estudados neste experimento ocorreu através das fezes, uma vez que na urina só apareceram sob forma de traços.

Os resultados do trabalho permitem concluir que:

- é possível manter éguas Puro Sangue Árabe, em reprodução, exclusivamente a pasto de Coast-cross (Cynodon dactylon);

- os parâmetros obtidos podem ser considerados como valores de referência para éguas Puro Sangue Árabe, em gestação, quando criadas nas condições do presente estudo, e

- os parâmetros obtidos podem auxiliar nos cálculos de dietas alimentares.

\section{RESUMO}

Em éguas Puro Sangue Árabe manejadas em pastagem de Coast-cross (Cynodon dactylon) foram determinados vários parâmetros bioquímicos no período inicial e final da gestação. Para o estudo foram coletados sangue, urina e fezes, alem de feitas medições corporais. As éguas ganharam, em média, 69,4 $\mathrm{kg}$ entre o inicio e final da prenhez. O nível de proteína total sangüínea aumentou $(\mathrm{P}<0,05)$ do primeiro ao último mês de gestação, enquanto que o de albumina diminuiu. A proporção albumina : proteína manteve-se constante, mostrando que a dieta protéica destes animais era equilibrada. Os níveis de cálcio, fósforo, magnésio, cobre e zinco no soro sangüíneo, e os de proteína total, glicose, creatinina e uréia da urina, não variaram durante a prenhez. Os níveis de cálcio e magnésio na urina aumentaram $(\mathrm{P}<0,05)$ do inicio ao final da gestação. O nível de fósforo e potássio diminuíram $(\mathrm{P}<0,05)$ no final da gestação, provavelmente em função do crescimento fetal. A analise dos resultados permite concluir que a maioria dos elementos estudados foram eliminados através da urina com exceção dos microminerais, eliminados através das fezes. Considerando o desenvolvimento corporal dos animais durante a prenhez, os parâmetros bioquímicos estudados poderiam ser considerados como de referência para éguas gestantes Puro Sangue Árabe manejadas exclusivamente em pastagem de Coast-cross. 


\section{REFERÊNCIAS BIBLIOGRÁFICAS}

Baucus, K .L.; Ralston, S. L.; Rich,G. A.\& Squires, E. L. (1989), The effect of copper and zinc supplementation on mineral content of mares milk. Equine Vet. Sci., 9 (4), 206-209.

Dietz, O. \& Wiesner, E. ed. (1984), Diseases of the horses. Part 1. Basel: Karger, pp.28-33.

Felbinger, U. (1987), Selected serum constituents in pregnant and lactating Thoroughbread mares. Israel J. Vet. Med., 42 (2), 96-102.

Fuentes-Garcia, F.; Vinuesa-Silva, M.; Herrera-Garcia, M.; Quiles, S. A. \& Aparicio, M. J. B. (1988), A study of some body measurements at birth in Andalusian and Arab horses. Arch. Zootec., 37 (139), 231-241.

Henneke, D. R.; Potter, G. D.; Kreider, J. L. \& Yates, B. F. (1983) Relationship between condition score, physical measurements and body fat percentage in mares. Equine Vet. J., 15 (4), 371-372.

Hines, K. K. (1985), Reproductive efficency and endocrine status of pospartum mares at different levels of body condition. Diss. Abs. Int. (B), 46 (6), 1834-1835.

Hintz, H. F. (1992), Nutrient requirments. In: Ralston, S. L. ed, Nutrition In: Current therapy in equine medicine. Philadelphia: W. B. Saunders Company, pp.715-717.

Meyer, H. \& Ahlswede, L. (1976), Über das intrauterine Wachstum und die Kö rperzusammensetzung von Folen sowie den Nahrstoffbedarf tragender Stuten. Tierernährung, 4, 263-292.

Microcal Origin (1996), Version 4.1, Northampton, MA: Microcal Software, 5 disquetes $31 / 2$ ".

National Research Council (1989), Nutrient requirements of horses. 5 ed., Washington: Ntional Academy Press, 100p.
Patterson, P. H.; Coon, C. N. \& Hughes, I. M. (1985), Protein requirements of mature working horses. J. Anim. Sci., 61 (1), 187-196.

Ralston, S. L. (1990), Clinical nutrition of adult horses. Equine Pract., 6 (2), 339-354.

Ralston, S. L. (1992), Diagnosis of commun mineral inbalances. In: Nutrition. In: Current therapy in equine medicine, Philadelphia: W.B. Saunders Company, pp.717-720.

Rossdale, P. D. \& Ricketts, S. W. (1980), Clinical and further examination. 2 ed., London: Baillière Tindall, 630p.

Rogers, P. A.; Fahey Jr., G. C. \& Albert, W. W. (1984), Blood metabolite profiles of broodmares and foals. Equine Vet. J., 16 (3), 192-196.

Silva, A. E. D. F.; Manzano, A.; Unanian, M. M.; Romano, M. A. \& Machado, D. C. (1990), Manejo da criação de eqüinos na EMBRAPA-UEPAE de São Carlos (Fazenda Chanchin). São Carlos-SP: EMBRAPA-UEPAE de São Carlos, 1990. 37p. (EMBRAPA-UEPAE São Carlos, Comunicado Técnico, 7).

Singh, R. P. \& Raut, B. (1986), Study of foaling pattern, birth weight, gestation period and fertility in equines of a equine breeding stud. J. Remount Vet. Corps, 25 (2), 109-120.

Unanian, M. M.; Silva, A. E. D. F.; Barbosa, P. F. \& Manzano, A. (1994), Características das condições corporais no desenvolvimento da prenhez em éguas. In: CONGRESSO BRASILEIRO DE MEDICINA VETERIANRIA, 23, Recife, PE., Anais...p.581.

Unanian, M. M.; Lepera, J. S. \& Pereira, A. C. (1994), Composição química do colostro de égua. 981-987.

Arq. Biol. Tecnol., 37 (4),

Wolter, R. (1975), Alimentacion del caballo. Zaragoza: Editorial Acriba, 172p. 